\title{
Validation of a Prediction Model for Vaginal Birth after Cesarean Delivery Reveals Unexpected Success in a Diverse American Population
}

\author{
Melanie Mai Maykin, MD ${ }^{1,2}$ Amanda J. Mularz, MD ${ }^{1,3}$ \\ Stephanie Gaw Valderramos, MD, PhD ${ }^{1,2}$ \\ ${ }^{1}$ Division of Maternal-Fetal Medicine, Department of Obstetrics and \\ Gynecology, University of California, Los Angeles, California \\ 2 Division of Maternal-Fetal Medicine, Department of Obstetrics, \\ Gynecology, and Reproductive Sciences, University of California, \\ San Francisco, California \\ ${ }^{3}$ Department of Maternal-Fetal Medicine, Obstetrix Medical Group of \\ Houston, Shenandoah, Texas
}

Lydia K. Lee, MD, PhD ${ }^{1}$

\begin{abstract}
Address for correspondence Stephanie Gaw Valderramos, MD, PhD, Division of Maternal-Fetal Medicine, Department of Obstetrics and Gynecology, University of California, 513 Parnassus Ave, Box 0556 16HSE, San Francisco, CA 94143

(e-mail: Stephanie.Valderramos@ucsf.edu).
\end{abstract}

Am J Perinatol Rep 2017;7:e31-e38.

\begin{abstract}
Keywords

- vaginal birth after cesarean

- trial of labor after cesarean

- MFMU VBAC calculator

- VBAC success

Objective To investigate the validity of a prediction model for success of vaginal birth after cesarean delivery (VBAC) in an ethnically diverse population.

Methods We performed a retrospective cohort study of women admitted at a single academic institution for a trial of labor after cesarean from May 2007 to January 2015. Individual predicted success rates were calculated using the Maternal-Fetal Medicine Units Network prediction model. Participants were stratified into three probability-ofsuccess groups: low $(<35 \%)$, moderate $(35-65 \%)$, and high $(>65 \%)$. The actual versus predicted success rates were compared.

Results In total, 568 women met inclusion criteria. Successful VBAC occurred in 402 (71\%), compared with a predicted success rate of $66 \%(p=0.016)$. Actual VBAC success rates were higher than predicted by the model in the low (57 vs. $29 \%$; $p<0.001$ ) and moderate (61 vs. $52 \% ; p=0.003$ ) groups. In the high probability group, the observed and predicted VBAC rates were the same (79\%).

Conclusion When the predicted success rate was above $65 \%$, the model was highly accurate. In contrast, for women with predicted success rates $<35 \%$, actual VBAC rates were nearly twofold higher in our population, suggesting that they should not be discouraged by a low prediction score.
\end{abstract}

The decision between a trial of labor after cesarean (TOLAC) or an elective repeat cesarean delivery (ERCD) can be difficult. A successful vaginal birth after cesarean delivery (VBAC) is associated with lower maternal mortality, a shorter postpartum recovery time, and a decreased risk of future pregnancy complications. Conversely, a failed TOLAC resulting in a cesarean delivery (CD) is associated with greater morbidity than ERCD. ${ }^{1}$

received July 28, 2016 accepted after revision January 3, 2017
DOI http://dx.doi.org/ 10.1055/s-0037-1599129. ISSN 2157-6998.
To aid in patient counseling, the Maternal-Fetal Medicine Units (MFMU) Network developed a prediction model from a large prospective U.S. cohort from 1999 to 2002 . $^{2}$ This model incorporates six maternal variables (age, body mass index [BMI], race, history of prior vaginal delivery, prior VBAC, and indication for prior cesarean) obtainable at the first prenatal visit to estimate an individualized, patient-specific likelihood of a successful VBAC. ${ }^{3}$ Subsequent studies have

Copyright $\odot 2017$ by Thieme Medical Publishers, Inc., 333 Seventh Avenue, New York, NY 10001, USA. Tel: +1(212) 584-4662.

\section{License terms}

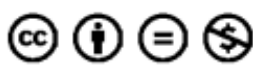


evaluated the external validity of this prediction model among various ethnic and geographic cohorts. ${ }^{4-9}$ All of these studies have found the model to be most accurate at higher predicted success rates, and most studies reported that observed rates were lower if predicted success was $<30$ to $40 \%$. However, the majority of these validation studies were performed in relatively homogenous populations where $>70 \%$ of patients were of a single dominant ethnicity. ${ }^{4,6-8}$

We hypothesized that the accuracy of this model may differ between institutions due to variations in patient populations. Our primary goal was to determine the applicability of this VBAC prediction model in an ethnically diverse U.S. population at a single university-based institution. Our secondary aim was to identify factors associated with higher- or lower-than-predicted success rates.

\section{Materials and Methods}

This study was approved by the Institutional Review Board of the University of California, Los Angeles (UCLA). UCLA Medical Center is a tertiary referral center with an ethnically diverse patient population ( - Table $\mathbf{1}$ ). The labor and delivery unit manages approximately 1,800 deliveries a year, and obstetrics and gynecology residents attend all births. Certified nurse midwives (CNMs) are the primary prenatal and labor provider for approximately $30 \%$ of patients.

All women who attempted a TOLAC between May 2007 and January 2015 were identified through the departmental delivery registry. The following patients were excluded: $<18$ years of age, fetal demise, lethal fetal anomalies, or incomplete medical records. The following maternal characteristics (used in the MFMU prediction model) ${ }^{2,3}$ were obtained from medical records: maternal age, BMI $\left(\mathrm{kg} / \mathrm{m}^{2}\right)$, ethnicity, any prior vaginal delivery, prior VBAC, and indication for prior $\mathrm{CD}$. If prepregnancy BMI was not available, the earliest available BMI calculation in pregnancy was used.

To explore the predictive value of factors that were not included in the MFMU model, additional data were examined. These included (1) antepartum variables, such as, chronic hypertension, diabetes, number of prior cesarean deliveries, and CNM or physician as primary prenatal and/or labor provider; (2) intrapartum variables such as spontaneous onset or induction of labor, augmentation of labor, epidural use, complications including chorioamnionitis, elevated blood pressures during labor (defined as systolic blood pressure $\geq 140$ or diastolic blood pressure $\geq 90$ ), and

Table 1 Study population characteristics

\begin{tabular}{|c|c|c|c|c|c|c|c|c|c|}
\hline $\begin{array}{l}\text { Group } \\
\text { Predicted success } \\
n\end{array}$ & \multicolumn{2}{|c|}{$\begin{array}{l}\frac{\text { Low }}{<35 \%} \\
n=30\end{array}$} & \multicolumn{2}{|c|}{$\begin{array}{l}\text { Moderate } \\
35-65 \% \\
n=229\end{array}$} & \multicolumn{2}{|c|}{$\begin{array}{l}\frac{\text { High }}{>65 \%} \\
n=309\end{array}$} & \multicolumn{2}{|c|}{$\begin{array}{l}\text { Total } \\
n=568\end{array}$} & $p$-Value ${ }^{a}$ \\
\hline Maternal age (y) & \multicolumn{2}{|c|}{$33 \pm 4.5$} & \multicolumn{2}{|c|}{$31.6 \pm 5.3$} & \multicolumn{2}{|c|}{$32.1 \pm 5.2$} & \multicolumn{2}{|c|}{$31.9 \pm 5.2$} & 0.279 \\
\hline BMI $\left(\mathrm{kg} / \mathrm{m}^{2}\right)^{\mathrm{b}}$ & \multicolumn{2}{|c|}{$37.13 \pm 7.9$} & \multicolumn{2}{|c|}{$28.24 \pm 5.1$} & \multicolumn{2}{|c|}{$26.09 \pm 5.6$} & \multicolumn{2}{|c|}{$27.54 \pm 6.1$} & $<0.001$ \\
\hline \multicolumn{10}{|l|}{ Ethnicity } \\
\hline Caucasian & 2 & $(6.7 \%)$ & 61 & $(26.6 \%)$ & 144 & $(46.6 \%)$ & 207 & $(36.4 \%)$ & \multirow[t]{5}{*}{$<0.001$} \\
\hline African-American & 4 & $(13.3 \%)$ & 16 & $(7 \%)$ & 11 & $(3.6 \%)$ & 31 & $(5.5 \%)$ & \\
\hline Hispanic/Latina & 24 & $(80 \%)$ & 122 & $(53.3 \%)$ & 83 & $(26.9 \%)$ & 229 & $(40.3 \%)$ & \\
\hline Asian & 0 & $(0.0 \%)$ & 15 & $(6.6 \%)$ & 27 & $(8.7 \%)$ & 42 & $(7.4 \%)$ & \\
\hline Other & 0 & $(0.0 \%)$ & 15 & $(6.6 \%)$ & 44 & $(14.2 \%)$ & 59 & $(10.4 \%)$ & \\
\hline Any prior VD & 0 & $(0.0 \%)$ & 14 & $(6.1 \%)$ & 152 & $(49.2 \%)$ & 166 & $(29.2 \%)$ & $<0.001$ \\
\hline Prior VBAC & 0 & $(0.0 \%)$ & 4 & $(1.7 \%)$ & 117 & $(37.9 \%)$ & 121 & $(21.3 \%)$ & $<0.001$ \\
\hline \multicolumn{10}{|l|}{ Number of prior CDs } \\
\hline 1 & 29 & $(96.7 \%)$ & 221 & $(96.5 \%)$ & 295 & (95.5\%) & 545 & $(96 \%)$ & \multirow[t]{2}{*}{0.82} \\
\hline 2 & 1 & $(3.3 \%)$ & 8 & $(3.5 \%)$ & 14 & $(4.5 \%)$ & 23 & $(4 \%)$ & \\
\hline \multicolumn{10}{|c|}{ Indication for prior CD } \\
\hline Arrest of dilation & 16 & $(53.3 \%)$ & 82 & $(35.8 \%)$ & 19 & $(6.1 \%)$ & 117 & $(20.6 \%)$ & \multirow[t]{5}{*}{$<0.001$} \\
\hline Arrest of descent & 7 & $(23.3 \%)$ & 54 & $(23.6 \%)$ & 18 & $(5.8 \%)$ & 79 & $(13.9 \%)$ & \\
\hline NRFHT & 2 & $(6.7 \%)$ & 38 & $(16.6 \%)$ & 93 & $(30.1 \%)$ & 133 & $(23.4 \%)$ & \\
\hline Malpresentation & 2 & $(6.7 \%)$ & 27 & $(11.8 \%)$ & 80 & $(25.9 \%)$ & 109 & $(19.2 \%)$ & \\
\hline Other & 3 & $(10 \%)$ & 28 & $(12.2 \%)$ & 99 & $(32 \%)$ & 130 & (22.9\%) & \\
\hline
\end{tabular}

Abbreviations: BMI, body mass index; $C D$, cesarean delivery; NRFHT, nonreassuring fetal heart tracing; $V D$, vaginal delivery; VBAC, vaginal birth after cesarean.

Note: Data are represented as mean \pm standard deviation or $n(\%)$.

${ }^{\mathrm{a}} \mathrm{p}$-Values were calculated by analysis of variance or chi-squared analysis as appropriate. ${ }^{\mathrm{b}} \mathrm{BMI}$ was based on earliest recorded BMI in the pregnancy. 
administration of magnesium sulfate, and (3) delivery variables such as gestational age at delivery, mode of delivery, and indication for repeat $\mathrm{CD}$. If the repeat $\mathrm{CD}$ was performed after patient request, without a clear obstetric indication, it was considered elective. The following postpartum outcomes were collected: birth weight, Apgar scores, symptomatic uterine rupture (confirmed in the operative report), and postpartum hemorrhage (defined as blood loss $>500 \mathrm{~mL}$ for vaginal delivery or $>1,000 \mathrm{~mL}$ for $\mathrm{CD}$ ).

Each patient's predicted VBAC success rate was calculated with the online MFMU VBAC calculator. ${ }^{3}$ Participants were then stratified into three groups representing "low" ( $<35 \%)$, "moderate" (35-65\%), and "high" (>65\%) predicted probability of success. These definitions were selected based on prior validation studies that showed differential performance of the model if the predicted success rate was either $<30$ to $40 \%$ or $>60$ to $70 \%{ }^{4-9}$ For each group, we calculated the mean predicted VBAC success rate from the individual patient scores and the observed success rate for each group. A two-tailed, one-way test of proportions was used to compare the mean predicted VBAC success probabilities of each of the three groups to the corresponding observed success rates. Analysis of variance or chi-squared analysis was used as appropriate to calculate $p$-values for continuous and noncontinuous variables, respectively. Backward stepwise logistic regression was performed to identify factors associated with successful VBAC; results were confirmed with tests for both specification error and goodness of fit. Stata 13.1 (College Station, TX) was used for all statistical analysis.

\section{Results}

During the study period, 595 women met the inclusion criteria and were examined for eligibility. Two patients were excluded for fetal demise, two patients were under the age of 18 , and three patients were excluded for lethal fetal anomalies. Twenty patients had incomplete records. In total, 568 (95.4\%) women were confirmed eligible and included in the analysis. In all, 402 women (70.8\%) had successful VBAC. A flow diagram of the final study population is depicted in -Fig. 1.

The predicted VBAC success rate was calculated for each patient, with a range of 17.1 to $96.3 \%$. Patients were then stratified into three groups by predicted success rate: "low" $(<35 \% ; n=30)$, "moderate" (35-65\%; $n=229)$, and "high" ( $>65 \% ; n=309$ ). Descriptive characteristics of the participants are presented in -Table $\mathbf{1}$. As expected, based on the variables included in the MFMU model, women in the low group were more likely to be obese, Latina or AfricanAmerican, or have a recurring indication for CD. Women in the high group were more likely to have had a prior vaginal delivery or prior VBAC. Maternal age did not segregate with the predicted likelihood of success $(p=0.279$ ).

For each group, the mean predicted VBAC success rates were calculated and compared with the mean actual VBAC success rate (-Fig. 2). For the low group, the mean predicted success rate was $29 \%$ and the actual VBAC success rate was $57 \%$, nearly twofold higher than estimated by the prediction model $(p=0.001 ; 95 \%$ confidence interval $[\mathrm{CI}]: 39-75 \%)$. For the moderate group, there was a $9 \%$ difference in predicted

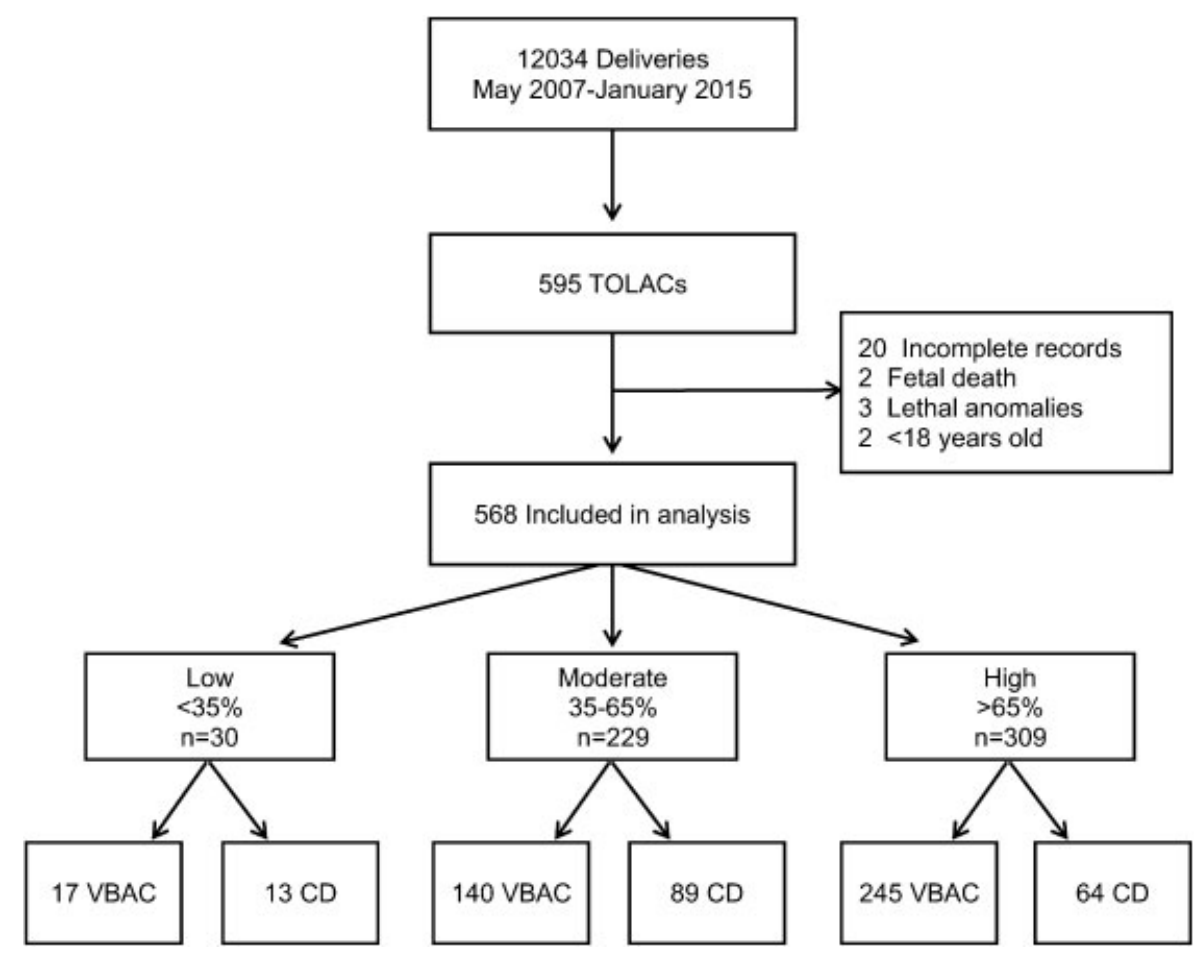

Fig. 1 Flow of study participants. CD, cesarean delivery; TOLAC, Trial of labor after cesarean; VBAC, vaginal birth after cesarean. 


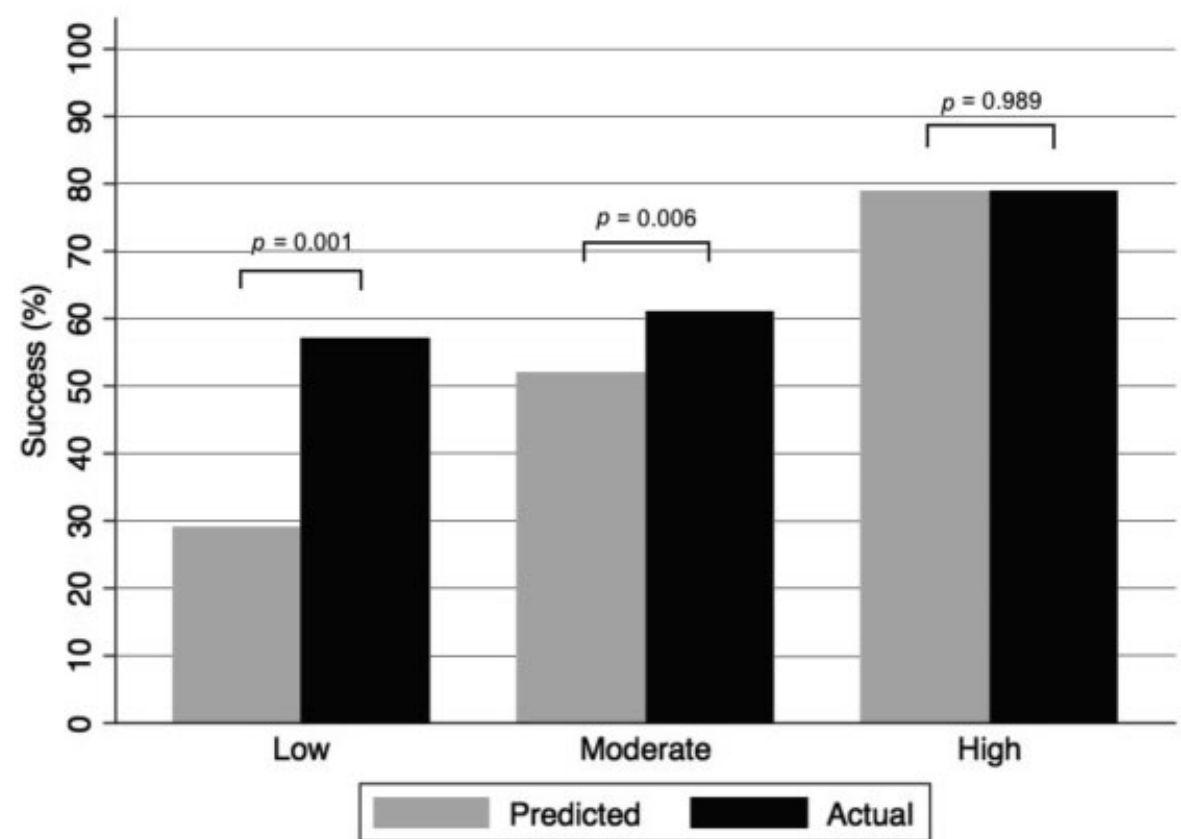

Fig. 2 Vaginal birth after cesarean (VBAC) outcomes by group. Mean predicted and actual VBAC rates of the low ( $<35 \%)$, moderate (35-65\%), and high $(>65 \%)$ predicted success groups and for the overall cohort. $p$-Values were calculated by two-tailed, one-way test of proportions.

versus actual success rates (52 vs. $61 \% ; p=0.006$; $\mathrm{CI}: 55-$ $67 \%$ ). There was no significant difference between predicted and actual success rates in the high group (79 and 79\%; $p=0.989$; CI: $75-84 \%)$. For the total cohort, the actual success rate was $71 \%$ compared with the predicted rate of $66 \%(p=0.016$; CI: $67-75 \%)$.

Given the finding of higher than predicted VBAC success rates in the low and moderate groups, we compared intrapartum variables between groups to assess for potential confounding factors (-Table 2 ). The rates of spontaneous onset, induction, and augmentation of labor were similar between the three groups. There was no difference in rates of preterm pregnancy or in birth weight. The incidence of diabetes was higher in the low group as compared with the moderate and high groups (23.3, 8.7, and 6.8\%, respectively; $p=0.008$ ). The low and moderate groups had higher rates of epidural use in labor compared with the high group (83.3, 81.7, and $72 \%$, respectively; $p=0.031)$. The percentage of patients managed by CNMs was not different between groups. Finally, there was no difference in the rates of intrapartum magnesium administration, chorioamnionitis, or elevated blood pressure between groups. No patients with

Table 2 Intrapartum variables by predicted success of VBAC

\begin{tabular}{|c|c|c|c|c|c|c|c|c|c|}
\hline $\begin{array}{l}\text { Group } \\
\text { Predicted success } \\
\text { n }\end{array}$ & \multicolumn{2}{|c|}{$\begin{array}{l}\text { Low } \\
\begin{array}{l}<35 \% \\
n=30\end{array}\end{array}$} & \multicolumn{2}{|c|}{$\begin{array}{l}\text { Moderate } \\
35-65 \% \\
n=229\end{array}$} & \multicolumn{2}{|c|}{$\begin{array}{l}\frac{\text { High }}{>65 \%} \\
n=309\end{array}$} & \multicolumn{2}{|c|}{$\begin{array}{l}\underline{\text { Total }} \\
n=568\end{array}$} & \multirow{2}{*}{$\begin{array}{l}p \text {-Value }{ }^{\mathrm{a}} \\
0.999\end{array}$} \\
\hline Spontaneous labor & 24 & $(80 \%)$ & 184 & $(80.3 \%)$ & 248 & $(80.3 \%)$ & 456 & $(80.3 \%)$ & \\
\hline Induction & 6 & $(20 \%)$ & 45 & $(19.7 \%)$ & 61 & $(19.7 \%)$ & 112 & $(19.7 \%)$ & 0.999 \\
\hline Augmentation & 17 & $(56.7 \%)$ & 115 & $(50.2 \%)$ & 136 & $(44 \%)$ & 268 & $(47.2 \%)$ & 0.157 \\
\hline Preterm pregnancy (<37 wk) & 2 & $(6.7 \%)$ & 9 & $(3.9 \%)$ & 20 & $(6.5 \%)$ & 31 & $(5.5 \%)$ & 0.42 \\
\hline Diabetes $^{\mathrm{b}}$ & 7 & $(23.3 \%)$ & 20 & $(8.7 \%)$ & 21 & $(6.8 \%)$ & 48 & $(8.5 \%)$ & 0.008 \\
\hline Birth weight $(\mathrm{g})$ & \multicolumn{2}{|c|}{$3,402 \pm 432$} & \multicolumn{2}{|c|}{$3,431 \pm 549$} & \multicolumn{2}{|c|}{$3,428 \pm 520$} & \multicolumn{2}{|c|}{$3,422 \pm 527$} & 0.934 \\
\hline Labor epidural & 25 & $(83.3 \%)$ & 187 & $(81.7 \%)$ & 224 & $(72.5 \%)$ & 436 & $(76.8 \%)$ & 0.031 \\
\hline CNM as primary provider & 6 & $(20 \%)$ & 68 & $(29.7 \%)$ & 92 & $(29.8 \%)$ & 166 & $(29.2 \%)$ & 0.521 \\
\hline Elevated blood pressure ${ }^{c}$ & 6 & $(20 \%)$ & 19 & $(8.3 \%)$ & 25 & $(8.1 \%)$ & 50 & $(8.8 \%)$ & 0.084 \\
\hline Intrapartum magnesium & 3 & $(10 \%)$ & 14 & $(6.1 \%)$ & 12 & $(3.9 \%)$ & 29 & $(5.1 \%)$ & 0.233 \\
\hline Chorioamnionitis & 2 & $(6.7 \%)$ & 21 & $(9.2 \%)$ & 13 & $(4.2 \%)$ & 36 & $(6.3 \%)$ & 0.065 \\
\hline
\end{tabular}

Abbreviations: CNM, certified nurse midwife; VBAC, vaginal birth after cesarean.

Note: Data are represented as mean \pm standard deviation or $n(\%)$.

${ }^{a} p$-Values were calculated by analysis of variance or chi-squared analysis as appropriate. ${ }^{b}$ Pregestational or gestational diabetes. ${ }^{c}$ Defined as systolic blood pressure $\geq 140$ and/or diastolic blood pressure $\geq 90$. 
Table 3 Perinatal outcomes by predicted success of VBAC

\begin{tabular}{|c|c|c|c|c|c|c|c|c|c|}
\hline \multirow{2}{*}{$\begin{array}{l}\text { Group } \\
\text { Predicted success } \\
n \\
\text { VBAC }\end{array}$} & \multicolumn{2}{|c|}{$\begin{array}{l}\text { Low } \\
\begin{array}{l}<35 \% \\
n=30\end{array}\end{array}$} & \multicolumn{2}{|c|}{$\begin{array}{l}\text { Moderate } \\
35-65 \% \\
n=229\end{array}$} & \multicolumn{2}{|c|}{$\begin{array}{l}\frac{\text { High }}{>65 \%} \\
n=309\end{array}$} & \multicolumn{2}{|c|}{$\begin{array}{l}\text { Total } \\
n=568\end{array}$} & \multirow{2}{*}{$\begin{array}{l}p \text {-Value }^{\mathrm{a}} \\
<0.001\end{array}$} \\
\hline & 17 & $(56.7 \%)$ & 140 & $(61.1 \%)$ & 245 & $(79.3 \%)$ & 402 & $(70.8 \%)$ & \\
\hline Indication for repeat CD & 13 & $(43.3 \%)$ & 89 & (38.9\%) & 64 & $(20.7 \%)$ & 166 & $(29.2 \%)$ & \multirow[t]{6}{*}{$<0.001$} \\
\hline Arrest of dilation & 5 & (38.5\%) & 29 & $(32.6 \%)$ & 18 & $(28.1 \%)$ & 52 & $(31.3 \%)$ & \\
\hline Arrest of descent & 3 & (23.1\%) & 24 & (27\%) & 14 & (21.9\%) & 41 & $(24.7 \%)$ & \\
\hline NRFHT & 3 & $(23.1 \%)$ & 26 & $(29.2 \%)$ & 23 & $(35.9 \%)$ & 52 & $(31.3 \%)$ & \\
\hline Elective & 0 & $(0.0 \%)$ & 6 & $(6.7 \%)$ & 5 & $(7.8 \%)$ & 11 & $(6.6 \%)$ & \\
\hline Other & 2 & $(15.4 \%)$ & 4 & $(4.5 \%)$ & 4 & $(6.3 \%)$ & 10 & $(6 \%)$ & \\
\hline 5-min Apgar $<7$ & 1 & $(3.3 \%)$ & 7 & $(3.1 \%)$ & 4 & $(1.3 \%)$ & 12 & $(2.1 \%)$ & 0.332 \\
\hline Uterine rupture & 1 & $(3.3 \%)$ & 6 & $(2.6 \%)$ & 3 & $(1 \%)$ & 10 & $(1.8 \%)$ & 0.283 \\
\hline Postpartum hemorrhage & 6 & $(20 \%)$ & 39 & $(17 \%)$ & 24 & $(7.8 \%)$ & 69 & (12.1\%) & 0.002 \\
\hline
\end{tabular}

Abbreviations: CD, cesarean delivery; NRFHT, nonreassuring fetal heart tracing; VBAC, vaginal birth after cesarean.

Data are represented as mean \pm standard deviation or $n(\%)$.

${ }^{a} p$-Values were calculated by analysis of variance or chi-squared analysis as appropriate.

multiple gestations or more than two prior CD attempted TOLAC.

Perinatal outcomes stratified by group are presented in - Table 3. The indication for repeat $C D$ varied between the groups $(p<0.001)$. Patients in the low group had a higher rate of $\mathrm{CD}$ for arrest of dilation, whereas patients in the high group were more likely to have $\mathrm{CD}$ for nonreassuring fetal heart tracing. There was no difference in the rate of 5minute Apgar score $<7(p=0.332)$. There were 10 cases of uterine rupture $(10 / 402 ; 1.8 \%)$, none of which resulted in a peripartum hysterectomy. The rate of postpartum hemorrhage was greatest in the low group $(20,17$, and $7.8 \%$ for the low, moderate, and high groups, respectively; $p=0.002$ ). There were no maternal or neonatal deaths.

We next examined the patient and perinatal factors grouped by VBAC success versus failure in our overall cohort (-Table 4). Consistent with prior studies, ${ }^{2,10}$ the successful VBAC group had lower rates of advanced maternal age (AMA) and higher rates of prior VD and prior VBAC. The percentage of patients with a recurring indication for CD (arrest of dilation or descent) was lower in the group that had successful VBAC. In contrast with the MFMU cohort, there was no difference in BMI or ethnicity between VBAC success and failure. Birth weight $>4,000 \mathrm{~g}$ was more common in failed TOL, as well as rates of chorioamnionitis, postpartum hemorrhage, and uterine rupture. There were no differences between the two groups for CNM as primary obstetric provider, epidural use, preterm pregnancy, diabetes, elevated blood pressures, intrapartum magnesium administration, and low 5-minute Apgar score.

Unadjusted odds ratios were calculated for these perinatal factors and VBAC success ( - Table $\mathbf{5}$ ). Of note, there were no associations between VBAC success, and BMI, ethnicity, CNM as labor provider, epidural use, preterm pregnancy, diabetes, elevated blood pressures, or intrapartum magnesium administration. Factors negatively associated with VBAC success were AMA, prior $C D$ for arrest of descent, induction or augmentation of labor, birth weight $>4,000 \mathrm{~g}$, chorioamnionitis, postpartum hemorrhage, and uterine rupture. VBAC success was positively associated with a history of prior VD, prior VBAC, prior CD for nonreassuring fetal heart tracing, and birth weight $<2,500 \mathrm{~g}$. Logistic regression found that only augmentation of labor and AMA made a significant contribution to the model; this was confirmed using tests for both specification error and goodness of fit.

\section{Discussion}

In summary, we evaluated the MFMU VBAC prediction model in an ethnically diverse U.S. population at a single universitybased hospital. In patients with $<65 \%$ predicted probability of success, the actual VBAC rates were significantly higher in our cohort. The outcomes were most striking for the group with predicted success rates $<35 \%$, for which observed VBAC success rates were $28 \%$ higher than predicted. Two of the six patient characteristics (BMI and ethnicity) used in the published prediction model were not predictive of VBAC success.

Overall VBAC success rates have been reported to be 60 to $80 \%{ }^{11}$ The model developed by the MFMU was based on a large U.S. cohort. ${ }^{2}$ To date, this model has been validated in multiple independent studies, some showing better model performance at low predicted success rates ${ }^{4}$ and others showing better performance at higher predicted probability. ${ }^{5-9}$ Our study adds to the current literature on the clinical use of this model. In contrast to published studies, which reported lower actual VBAC rates at lower predicted probabilities, the model greatly underestimated the probability of success in our study's low group.

Patient ethnicity and BMI, two predictors of VBAC success in the model, were not associated with success in our cohort. In contrast to the original MFMU cohort and subsequent validation cohorts, we had more patients of Latina, Asian, and other non-Caucasian ethnicities, and fewer AfricanAmericans. The prepregnancy BMI, used in the MFMU model, 
Table 4 Patient characteristics, obstetric factors, and perinatal outcomes by VBAC success

\begin{tabular}{|c|c|c|c|c|c|c|c|}
\hline \multirow[b]{2}{*}{ Advanced maternal age ( $\geq 35 \mathrm{y}$ ) } & \multicolumn{2}{|c|}{$\begin{array}{l}\text { Total } \\
(n=568)\end{array}$} & \multicolumn{2}{|c|}{$\begin{array}{l}\text { VBAC } \\
(n=402)\end{array}$} & \multicolumn{2}{|c|}{$\begin{array}{l}\text { Failed TOL } \\
(n=166)\end{array}$} & \multirow{2}{*}{$\begin{array}{l}p \text {-Value } \\
0.024\end{array}$} \\
\hline & 193 & $(34 \%)$ & 125 & $(31.1 \%)$ & 68 & $(41 \%)$ & \\
\hline BMI $\left(\mathrm{kg} / \mathrm{m}^{2}\right) \geq 30^{\mathrm{b}}$ & 185 & $(32.6 \%)$ & 130 & $(32.3 \%)$ & 55 & $(33.1 \%)$ & 0.854 \\
\hline \multicolumn{8}{|l|}{ Ethnicity } \\
\hline Caucasian & 207 & $(36.4 \%)$ & 152 & $(37.8 \%)$ & 55 & $(33.1 \%)$ & \multirow[t]{5}{*}{0.34} \\
\hline African-American & 31 & $(5.5 \%)$ & 19 & $(4.7 \%)$ & 12 & $(7.2 \%)$ & \\
\hline Hispanic/Latina & 229 & $(40.3 \%)$ & 160 & $(39.8 \%)$ & 69 & $(41.6 \%)$ & \\
\hline Asian & 42 & $(7.4 \%)$ & 33 & $(8.2 \%)$ & 9 & $(5.4 \%)$ & \\
\hline Other & 59 & $(10.4 \%)$ & 38 & $(9.5 \%)$ & 21 & $(12.7 \%)$ & \\
\hline Any prior VD & 166 & $(29.2 \%)$ & 142 & $(35.3 \%)$ & 24 & $(14.5 \%)$ & $<0.001$ \\
\hline Prior VBAC & 121 & $(21.3 \%)$ & 109 & $(27.1 \%)$ & 12 & $(7.2 \%)$ & $<0.001$ \\
\hline \multicolumn{8}{|l|}{ Indication for prior CD } \\
\hline Arrest of dilation & 117 & $(20.6 \%)$ & 77 & $(19.2 \%)$ & 40 & $(24.1 \%)$ & \multirow[t]{5}{*}{$<0.001$} \\
\hline Arrest of descent & 79 & $(13.9 \%)$ & 46 & $(11.4 \%)$ & 33 & (19.9\%) & \\
\hline NRFHT & 133 & $(23.4 \%)$ & 105 & $(26.1 \%)$ & 28 & (16.9\%) & \\
\hline Malpresentation & 109 & $(19.2 \%)$ & 81 & $(20.1 \%)$ & 28 & $(16.9 \%)$ & \\
\hline Other & 130 & $(22.9 \%)$ & 93 & $(23.1 \%)$ & 37 & $(22.3 \%)$ & \\
\hline \multicolumn{8}{|l|}{ Labor type } \\
\hline Spontaneous & 456 & $(80.3 \%)$ & 336 & $(83.6 \%)$ & 120 & $(72.3 \%)$ & 0.002 \\
\hline Induction & 112 & $(19.7 \%)$ & 66 & $(16.4 \%)$ & 46 & $(27.7 \%)$ & 0.002 \\
\hline Augmentation & 268 & $(47.2 \%)$ & 165 & $(41 \%)$ & 103 & $(62 \%)$ & $<0.001$ \\
\hline Preterm pregnancy $(<37 w)$ & 31 & $(5.5 \%)$ & 25 & $(6.2 \%)$ & 16 & $(9.6 \%)$ & 0.214 \\
\hline Diabetes $^{c}$ & 48 & $(8.5 \%)$ & 34 & $(8.5 \%)$ & 14 & $(8.4 \%)$ & 0.99 \\
\hline \multicolumn{8}{|l|}{ Birth weight (g) } \\
\hline$<2,500$ & 22 & $(3.9 \%)$ & 20 & $(5 \%)$ & 2 & $(1.2 \%)$ & \multirow[t]{3}{*}{0.001} \\
\hline $2,500-3,999$ & 473 & $(83.3 \%)$ & 342 & $(85.1 \%)$ & 131 & $(78.9 \%)$ & \\
\hline$\geq 4,000$ & 73 & $(12.9 \%)$ & 40 & $(10 \%)$ & 33 & $(19.9 \%)$ & \\
\hline Labor epidural & 436 & $(76.8 \%)$ & 301 & $(74.9 \%)$ & 135 & $(81.3 \%)$ & 0.1 \\
\hline CNM as primary provider & 166 & $(29.2 \%)$ & 116 & $(28.9 \%)$ & 50 & $(30.1 \%)$ & 0.76 \\
\hline Elevated blood pressure $^{d}$ & 50 & $(8.8 \%)$ & 35 & $(8.7 \%)$ & 15 & $(9 \%)$ & 0.9 \\
\hline Intrapartum magnesium & 29 & $(5.1 \%)$ & 20 & $(5 \%)$ & 9 & $(5.4 \%)$ & 0.826 \\
\hline Chorioamnionitis & 36 & $(6.3 \%)$ & 18 & $(4.5 \%)$ & 18 & $(10.8 \%)$ & 0.005 \\
\hline \multicolumn{8}{|l|}{ Complications } \\
\hline 5-min Apgar $<7$ & 12 & $(2.1 \%)$ & 7 & $(1.7 \%)$ & 5 & $(3 \%)$ & 0.338 \\
\hline Postpartum hemorrhage & 69 & $(12.1 \%)$ & 26 & $(6.5 \%)$ & 43 & $(25.9 \%)$ & $<0.001$ \\
\hline Uterine rupture & 10 & $(1.8 \%)$ & 3 & $(0.7 \%)$ & 7 & $(4.2 \%)$ & 0.004 \\
\hline
\end{tabular}

Abbreviations: AMA, advanced maternal age; BMI, body mass index; $C D$, cesarean delivery; CNM, certified nurse midwife; NRFHT, nonreassuring fetal heart tracing; TOL, trial of labor; VBAC, vaginal birth after cesarean; VD, vaginal delivery.

Note: Data are represented as mean \pm standard deviation or $n(\%)$.

${ }^{\mathrm{a}} \mathrm{p}$-Values were calculated by analysis of variance or chi-squared analysis as appropriate. ${ }^{\mathrm{b}} \mathrm{BMI}$ was based on earliest recorded BMI in the pregnancy.

'Pregestational or gestational diabetes. ${ }^{\mathrm{d} D e f i n e d}$ as systolic blood pressure $\geq 140$ and/or diastolic blood pressure $\geq 90$.

was not available for all of our patients. As is commonly done in clinical practice, we used the earliest recorded BMI in pregnancy, which may have contributed to differing results.

The most serious complication of TOLAC is uterine rupture, a risk that increases with the number of prior
CD. ${ }^{1,11}$ Our overall VBAC success rate of $71 \%$ was coupled with an overall uterine rupture rate of $1.8 \%$. Uterine rupture was associated with higher maternal morbidity, including TOLAC failure and postpartum hemorrhage. Of note, all cases of uterine rupture occurred in patients with only 
Table 5 Obstetrical variables and successful VBAC

\begin{tabular}{|c|c|}
\hline & Odds ratio $(95 \% \mathrm{Cl})$ \\
\hline Advanced maternal age ( $\geq 35 \mathrm{y})$ & $0.65(0.45-0.95)$ \\
\hline $\operatorname{BMI}\left(\mathrm{kg} / \mathrm{m}^{2}\right) \geq 30^{\mathrm{a}}$ & $0.96(0.66-1.42)$ \\
\hline \multicolumn{2}{|l|}{ Ethnicity } \\
\hline Caucasian & $1.23(0.84-1.79)$ \\
\hline African-American & $0.64(0.31-1.32)$ \\
\hline Hispanic/Latina & $0.93(0.64-1.34)$ \\
\hline Asian & $1.56(0.74-3.28)$ \\
\hline Other & $0.72(0.41-1.26)$ \\
\hline Any prior VD & $3.23(2.00-5.21)$ \\
\hline Prior VBAC & $4.77(2.57-8.85)$ \\
\hline \multicolumn{2}{|l|}{ Indication for prior CD } \\
\hline Arrest of dilation & $0.75(0.48-1.15)$ \\
\hline Arrest of descent & $0.52(0.32-0.85)$ \\
\hline NRFHT & $1.73(1.1-2.73)$ \\
\hline Malpresentation & $1.24(0.78-2.00)$ \\
\hline Other & $1.05(0.68-1.61)$ \\
\hline \multicolumn{2}{|l|}{ Labor type } \\
\hline Spontaneous & $1.95(1.27-3.00)$ \\
\hline Induction & $0.51(0.33-0.79)$ \\
\hline Augmentation & $0.43(0.29-0.62)$ \\
\hline Preterm pregnancy (<37w) & $1.76(0.73-4.27)$ \\
\hline Diabetes $^{\mathrm{b}}$ & $1.00(0.52-1.92)$ \\
\hline \multicolumn{2}{|l|}{ Birth weight (g) } \\
\hline$<2,500$ & $4.29(1.1-12.46)$ \\
\hline 2,500-3,999 & $1.52(0.96-2.41)$ \\
\hline$\geq 4,000$ & $0.45(0.27-0.73)$ \\
\hline Labor epidural & $0.68(0.44-1.07)$ \\
\hline CNM as primary provider & $0.94(0.63-1.4)$ \\
\hline Elevated blood pressure $^{c}$ & $0.96(0.51-1.81)$ \\
\hline Intrapartum magnesium & $0.91(0.41-2.05)$ \\
\hline Chorioamnionitis & $0.39(0.2-0.76)$ \\
\hline \multicolumn{2}{|l|}{ Complications } \\
\hline 5-min Apgar <7 & $0.57(0.18-1.82)$ \\
\hline Postpartum hemorrhage & $0.20(0.12-0.34)$ \\
\hline Uterine Rupture & $0.17(0.04-0.67)$ \\
\hline
\end{tabular}

Abbreviations: $\mathrm{BMI}$, body mass index; $\mathrm{CD}$, cesarean delivery; $\mathrm{Cl}$, confidence intervals; CNM, certified nurse midwife; NRFHT, nonreassuring fetal heart tracing; VBAC, vaginal birth after cesarean; VD, vaginal delivery.

Note: Cls that do not cross 1.0 are shown in bold.

${ }^{\mathrm{a}} \mathrm{BMI}$ was based on earliest recorded BMI in the pregnancy. ${ }^{\mathrm{b}}$ Pregestational or gestational diabetes. ${ }^{c}$ Defined as systolic blood pressure $\geq 140$ and/or diastolic blood pressure $\geq 90$.

one prior $\mathrm{CD}$. There were no hysterectomies, maternal deaths, nor neonatal deaths.

The ethnically diverse cohort described in our study is representative of many areas of the United States. The broad inclusion criteria, including preterm deliveries and more than one prior $\mathrm{CD}$, increase our study's generalizability. Our patient cohort also has a large percentage of patients (10\%) with a predicted score of $<40 \%$. The primary limitation of our study is possible selection bias due to the retrospective design. Our study is not powered to completely exclude associations with variables reported in this and prior studies. $^{12}$

Likely, additional unmeasured variables also influence VBAC outcomes, such as patient preferences, provider characteristics, and obstetric practice variations. Interestingly, no patients in the low group chose to end their TOLAC and undergo ERCD (vs. 6.7 and $7.8 \%$ in the moderate and high groups, respectively), suggesting that patients in this group were highly motivated to achieve a VBAC despite a low prediction score. Furthermore, patients that chose a CNM as their provider may have had a stronger preference for vaginal delivery. Although a large percentage of our cohort (29\%) was managed by CNMs, we found no association between VBAC success and provider type. Provider management styles may contribute to TOLAC success, as a recent study showed that providers with greater coping skills and lower anxiety levels had higher rates of VBAC. ${ }^{12}$

Lastly, institutional culture and local practice patterns could influence VBAC success rates. Fagerberg et al improved the predictive accuracy of the model by incorporating specific delivery ward $\mathrm{CD}$ rates into the algorithm. ${ }^{8}$ At our institution, TOLAC counseling is performed early in prenatal care by the primary obstetric provider. TOLAC is encouraged by the majority of providers, although we do not have data on TOLAC uptake rates. While styles may vary slightly among providers, our management of induction and augmentation of labor in TOLAC patients relies on Foley balloon and/or oxytocin. Tertiary referral hospitals equipped with resources to deal with obstetric emergencies may have increased institutional support of higher risk TOLACs, leading to improved success rates. Furthermore, data from which the MFMU model was derived were collected from 1999 to 2002, and obstetric management guidelines have since evolved to encourage a more permissive definition of normal labor progression. ${ }^{13,14}$

Prior studies have reported that the risk-benefit ratio for TOLAC versus ERCD shifts in favor of ERCD at predicted success rates of less than $70 \%{ }^{15}$ Patients may be influenced away from TOLAC in the setting of low predicted success. Indeed, most studies have shown a low rate of TOLACs with predicted VBAC success $<40 \%$, ranging from 0 to $8 \%{ }^{4-9}$ Nevertheless, we show that successful VBAC rates of almost $60 \%$ can be achieved despite predicted rates of $<35 \%$. As part of efforts to safely decrease cesarean rates in the United States, patients interested in TOLAC (and their providers) should not be discouraged by a low predicted success score.

Conflict of Interest

The authors report no conflict of interest. 


\section{Note}

Presented in part in poster format at the 70th Annual Meeting of the Obstetrical and Gynecological Society of Southern California, May 8-9, 2015, Marina del Rey, California.

\section{References}

1 Guise JM, Denman MA, Emeis C, et al. Vaginal birth after cesarean: new insights on maternal and neonatal outcomes. Obstet Gynecol 2010;115(06):1267-1278

2 Grobman WA, Lai Y, Landon MB, et al; National Institute of Child Health and Human Development (NICHD) Maternal-Fetal Medicine Units Network (MFMU). Development of a nomogram for prediction of vaginal birth after cesarean delivery. Obstet Gynecol 2007;109(04):806-812

3 Calculator - (MFMU) Network. VBAC calculator. Available at: https://mfmu.bsc.gwu.edu/PublicBSC/MFMU/VGBirthCalc/vagbirth.html. Retrieved November 19, 2015

4 Costantine MM, Fox K, Byers BD, et al. Validation of the prediction model for success of vaginal birth after cesarean delivery. Obstet Gynecol 2009;114(05):1029-1033

5 Chaillet N, Bujold E, Dubé E, Grobman WA. Validation of a prediction model for vaginal birth after caesarean. J Obstet Gynaecol Can 2013;35(02):119-124

6 Yokoi A, Ishikawa K, Miyazaki K, Yoshida K, Furuhashi M, Tamakoshi K. Validation of the prediction model for success of vaginal birth after cesarean delivery in Japanese women. Int J Med Sci 2012;9(06):488-491

7 Schoorel EN, Melman S, van Kuijk SM, et al. Predicting successful intended vaginal delivery after previous caesarean section: external validation of two predictive models in a Dutch nationwide registration-based cohort with a high intended vaginal delivery rate. BJOG 2014;121(07):840-847, discussion 847
8 Fagerberg MC, Maršál K, Källén K. Predicting the chance of vaginal delivery after one cesarean section: validation and elaboration of a published prediction model. Eur J Obstet Gynecol Reprod Biol 2015;188:88-94

9 Metz TD, Allshouse AA, Faucett AM, Grobman WA. Validation of a vaginal birth after cesarean delivery prediction model in women with two prior cesarean deliveries. Obstet Gynecol 2015;125(04): 948-952

10 Landon MB, Leindecker S, Spong CY, et al; National Institute of Child Health and Human Development Maternal-Fetal Medicine Units Network. The MFMU Cesarean Registry: factors affecting the success of trial of labor after previous cesarean delivery. Am J Obstet Gynecol 2005;193(3 Pt 2):1016-1023

11 National Institutes of Health Consensus Development Conference Panel. National Institutes of Health Consensus Development conference statement: vaginal birth after cesarean: new insights March 8-10, 2010. Obstet Gynecol 2010;115(06):1279-1295

12 Yee LM, Liu LY, Grobman WA. Relationship between obstetricians cognitive and affective traits and delivery outcomes among women with a prior cesarean. Am J Obstet Gynecol 2015;213(03):413.e1-413.e7

13 Spong CY, Berghella V, Wenstrom KD, Mercer BM, Saade GR. Preventing the first cesarean delivery: summary of a joint Eunice Kennedy Shriver National Institute of Child Health and Human Development, Society for Maternal-Fetal Medicine, and American College of Obstetricians and Gynecologists Workshop. Obstet Gynecol 2012;120(05):1181-1193

14 American College of Obstetricians and Gynecologists; Society for Maternal-Fetal Medicine. Obstetric care consensus no. 1: safe prevention of the primary cesarean delivery. Obstet Gynecol 2014;123:693-711

15 Grobman WA, Lai Y, Landon MB, et al; Eunice Kennedy Shriver National Institute of Child Health and Human Development Maternal-Fetal Medicine Units Network. Can a prediction model for vaginal birth after cesarean also predict the probability of morbidity related to a trial of labor? Am J Obstet Gynecol 2009; 200(01):56.e1-56.e6 